\title{
A RARE CASE OF CONGENITAL PULMONARY AIRWAY MALFORMATION ASSOCIATED WITH INTRALOBAR PULMONARY SEQUESTRATION IN AN ADULT - GASE REPORT
}

\section{Suciu Bogdan Andreī', Hălmaciu loana1, Bud Vasile', Mezei Tỉbor', Molnar Călin', Brînzaniuc Klara1, Ivănescu Adrian'}

${ }^{1}$ University of Medicine, Pharmacy, Science and Technology Tîrgu Mureș

Ioana Hălmaciu

University of Medicine, Pharmacy, Science and Technology Tîrgu Mureș, 38 Gheorghe Marinescu, 540142, Tîrgu Mureș, România email: anca_halmaciu@yahoo.com phone: +40740091324

\begin{abstract}
The congenital pulmonary airway malformations (CPAM) are extremely rare malformations which are most frequently diagnosed before birth or during childhood and are extremely rarely diagnosed in adults. Sometimes, type II CPAM can be associated with pulmonary sequestrations (PS), especially those extralobar. We present the case of a 39 years old female without any known previous respiratory symptoms until this age, who has having for approximatively 2 months repeated episodes of haemoptysis. The angio-CT exam showed the existence of multiple cyst-like formations in the left inferior pulmonary lobe (LLL) and 2 arteries starting from thoracic aorta that participated at the vascularization of the LLL. We performed a left inferior lobectomy and the postoperative evolution was favorable. The histopathological exam confirmed the diagnosis of type I CPAM associated with intralobar PS. The particularity of the presented case is given by the fact that this patient of 39 years old had no previous respiratory symptoms and no cases of type I CPAM associated with intralobar PS were cited before.
\end{abstract}

Keywords : congenital pulmonary airway malformation, pulmonary sequestration

\section{Introduction}

The congenital pulmonary airway malformations (CPAM) are extremely rare malformations, usually isolated, and rarely can be associated with other malformations such as: pulmonary sequestrations (PS), cardiac or renal malformations. Usually these anomalies are diagnosed before birth or during childhood and are extremely rarely diagnosed in adults. (1)

\section{Case report}

We report the case of a 39 years old female, who for approximatively 2 months before entering our service has been having repeated episodes of haemoptysis. Until this age the patient has no previous respiratory symptoms.

The angio-CT highlighted the existence of multiple cyst-like lesions, size between $6-83 \mathrm{~mm}$ in the left lower lobe (LLL), with presence of air and fluid levels, surrounded by a large area of consolidation. Also we noticed 2 arteries starting from the thoracic aorta that participated at the vascularization of the LLL, raising the suspicion of intralobar PS. (Figure 1) The bronchoscopy exam highlighted that the left inferior lobar bronchus has a reduced diameter of $4 \mathrm{~mm}$. 


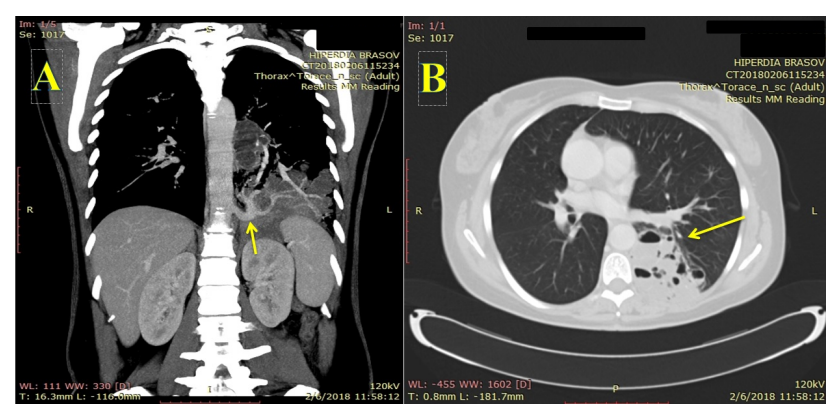

Figure 1: A: Angio-CT coronal image, showing an arterial branch of the thoracic aorta which vascularises the LLL; B: Angio-CT axial image showing the existence of multiple cyst-like lesions in the $L L L$

During the surgery, we found the existence of multiple cyst-like lesions in the LLL and the existence of 2 arteries with a caliber of $3 \mathrm{~mm}$ was noticed coming from the thoracic aorta and participating at the vascularization of the LLL(which have been ligated). The left lower lobar bronchus was hypoplasic. (Figure 2) We performed a left inferior lobectomy. The postoperative evolution was favourable. The histopathologic exam confirmed the diagnosis of type I CPAM associated with intralobar PS.

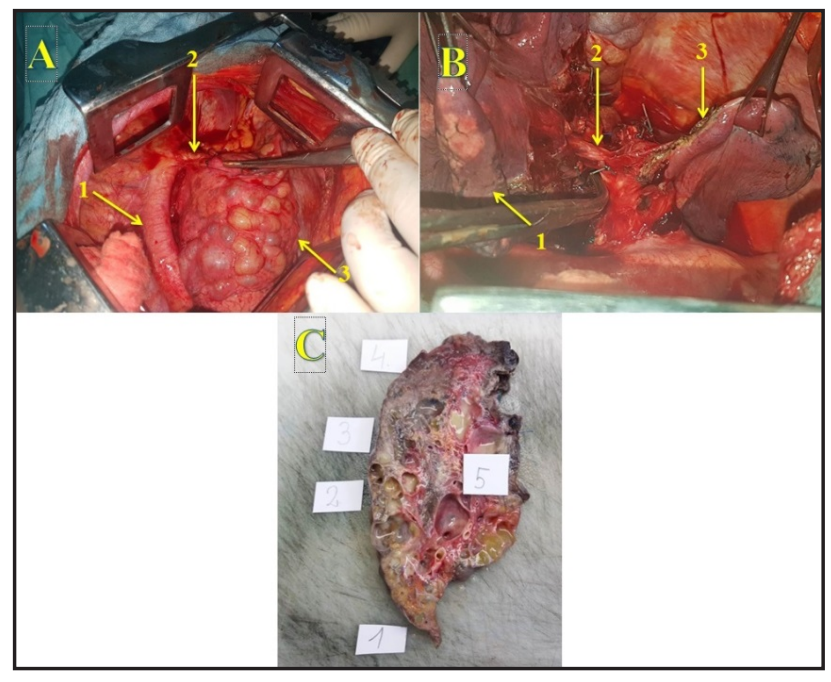

Figure 2: A(Intraoperative image) : 1-thoracic aorta, 2-2 arterial branches coming from the thoracic aorta and participating at the vascularization of the LLL(one is ligatured), 3-multiple cyst-like lesions in the LLL, B(Intraoperative image) : 1-LLL, 2-Hypoplasic left lower lobar bronchus, 3-left upper lobe; C(The surgical specimen) : 1-the base of the LLL, 2,3-the costal face of the LLL, 4-the apex of the LLL, 5-cyst-like lesions in the $L L L$

\section{Discussion}

The most frequent congenital pulmonary cyst-like lesions are: the congenital lobe emphysema, the cystic adenomatoid congenital malformation and the bronchogenic pulmonary cysts. All these cystic pulmonary anomalies are part of bronchopulmonary foregut malformations. (2)

CPAM is characterized by an excessive proliferation of mesenchymal cells. In the pulmonary parenchyma multiple cysts are formed which communicate with some bronchi, and therefore favouring the hyperinflation of these cyst-like formations. (3)

The PS appears due to anomalies in the embryological life due to an anomalous separation of the pulmonary vessels from the systemic vessels. Usually, the patients with extralobar sequestrations show no symptoms, while patients with intralobar sequestrations frequently show repetitive pneumonias.(2)

Type I CPAM is characterised by the existence multipe cystic lesions in the lung with a diameter of 2-10 $\mathrm{cm}$, but type II CPAM is characterised by the existence of multiple cystic lesions in the lung with a diameter between 0.5-2 $\mathrm{cm}$. Sometimes, type II CPAM can be associated with a PS, most frequently extralobar. (4)

It is a known fact that CPAM can determine in time the formation of different types of lung cancers. Therefore, for adult patients it is recommended that these malformations should be removed and a surgical intervention is mandatory. Usually, in these cases the performance of a lobectomy is recommended. (5)

The particularity of the presented case is given by the fact that this patient of 39 years old had no previous respiratory symptoms and no cases of type I CPAM associated with PS were cited before.

\section{References}

1. Strumiłło B, Jóźwiak A, Pałka A, Szaflik K, Piaseczna-Piotrowska A. Congenital cystic adenomatoid malformation-diagnostic and therapeutic procedure: 8-year experience of one medical centre. Kardiochirurgia i 
torakochirurgia polska $=$ Polish journal of cardio-thoracic surgery. 2018 Mar;15(1):10.

2. Takeda SI, Miyoshi S, Inoue M, Omori KI, Okumura M, Yoon HE, Minami M, Matsuda H. Clinical spectrum of congenital cystic disease of the lung in children. European journal of cardio-thoracic surgery. 1999 Jan $1 ; 15(1): 11-7$.

3. Haller JA, Golladay ES, Pickard LR, Tepas JJ, Shorter NA, Shermeta DW. Surgical management of lung bud anomalies: lobar emphysema, bronchogenic cyst, cystic adenomatoid malformation, and intralobar pulmonary sequestration. The Annals of thoracic surgery. $1979 \mathrm{Jul}$ 1;28(1):33-43.

4. Gross GW. Pediatric chest imaging. Current opinion in radiology. 1992;4(5):36-43.

5. Fievet L, Natale C, D'Journo XB, Coze S, Dubus JC, Guys JM, Thomas P, De Lagausie P. Congenital pulmonary airway malformation and sequestration: Two standpoints for a single condition. Journal of minimal access surgery. 2015 Apr;11(2):129-133. 